\title{
Aortoesophageal fistula secondary to stent-graft repair of the thoracic aorta after previous surgical coarctation repair
}

\author{
Kirkpatrick C. Santo, FRCS, Peter Guest, FRCP, FRCR, lan McCafferty, MRCP, FRCR, \\ and Robert S. Bonser, MD, FRCP, FRCS, FESC, Birmingham, United Kingdom
}

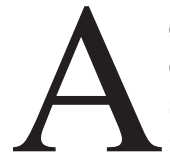

ortoesophageal fistula (AEF) is a highly lethal cause of massive gastrointestinal bleeding and a catastrophic complication after thoracic endovascular stent-graft aortic reconstruction (TEVAR). ${ }^{1}$ We report the management of AEF developing after TEVAR of a pseudoaneurysm of the descending aorta after coarctation repair.

\section{Clinical Summary}

A 31-year-old woman was admitted to a peripheral hospital with an episode of massive hematemesis. She had undergone a patchtechnique coarctation repair at age 3 years and required balloon dilatation for recoarctation at age 14 years. Annual cardiologic follow-up detected, at age 26 years, a pseudoaneurysm at the coarctation site with dimensions of $2.4 \times 1.9 \mathrm{~cm}$. The pseudoaneurysm size remained stable, but 8 months before the hematemesis, TEVAR was recommended to avert any risk of rupture and a Jomed $48 \times 20-\mathrm{mm}$ covered stent (Abbott Vascular Ltd, Kent, United Kingdom) was deployed at the coarctation site pseudoaneurysm. Post-TEVAR imaging suggested satisfactory exclusion.

After the hematemesis, she underwent esophagogastroduodenoscopy, which showed a 1.5-cm bluish polypoid lesion $26 \mathrm{~cm}$ from the incisura. Biopsy revealed blood clot only. She was discharged but readmitted 4 weeks later with a further massive hematemesis. A repeat esophagogastroduodenoscopy revealed that the lesion had enlarged 3-fold. This finding, together with the history of coarctation surgery, prompted a computed tomographic (CT) scan (Figure 1), which demonstrated a perigraft hematoma suggestive of AEF. After transfer to our center, aortography confirmed peri-stent-graft extravasation, further supporting a diagnosis of AEF. Another covered stent $(38 \times 12 \mathrm{~mm}$, Jostent; Abbott Vascular Ltd) was deployed and the hematemesis abated. However, a postprocedure angiogram demonstrated persistent filling of the pseudoaneurysm. The incomplete pseudoaneurysm exclusion and the perceived risk of further complications prompted surgical referral.

Echocardiography demonstrated moderate bicuspid aortic valve stenosis. Surgery was performed via a transsternal thoracotomy in the left fourth intercostal space and comprised mechanical

From the Department of Cardiac Surgery, University Hospital Birmingham NHS Trust, Birmingham, United Kingdom.

Received for publication July 19, 2007; accepted for publication Aug 7, 2007.

Address for reprints: Professor Robert S. Bonser, Department of Cardiac Surgery, Queen Elizabeth Hospital, Birmingham B15 2TH, United Kingdom (E-mail: Robert.Bonser@uhb.nhs.uk).

J Thorac Cardiovasc Surg 2007;134:1585-6

$0022-5223 / \$ 32.00$

Copyright () 2007 by The American Association for Thoracic Surgery

doi:10.1016/j.jtcvs.2007.08.027

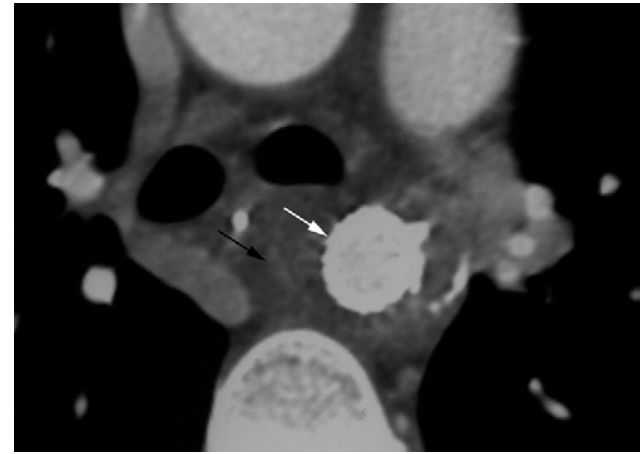

Figure 1. A stent (white arrow) is identified in the distal aortic arch. Other views demonstrated persistent flow into the left subclavian artery confirming endoleakage. There is mediastinal hematoma (black arrow) between the aorta and esophagus consistent with the pseudoaneurysm formation.

aortic valve replacement, retrocardiac ascending-descending aortic conduit insertion, and an interposition graft between the conduit and the left subclavian artery. The aortic arch was staple-ligated between the left common carotid artery and the left subclavian artery. The descending aorta was stapled below the stent site. The aortic pseudoaneurysm was opened and the previously placed stents were removed. Inspection revealed a section of necrotic and partially absent aortic wall with erosion of the longitudinal esophageal muscle but no mucosal breach. It was assumed that stent deployment had perforated or disintegrated the aortic wall leading to an AEF. The aortic remnant was left open, a feeding enterostomy and decompression gastrostomy performed, and the chest closed with drainage. Recovery was uneventful, with a contrast swallow examination showing no abnormalities. At 12 months, the patient remains free of symptoms, and CT scan (Figure 2) demonstrates resolution of perigraft hematoma and satisfactory anatomic reconfiguration.

\section{Discussion}

The incidence of late aortic aneurysm formation after repair of coarctation of the aorta ranges from $1 \%$ to $32 \%$, and $7 \%$ present with fatal rupture including $\mathrm{AEF}^{2}$ Aneurysm incidence is highest in patients with synthetic patch aortoplasty. Although TEVAR has been used to manage such cases of AEF, it may also lead to AEF in 5\% of descending aortic TEVAR procedures. ${ }^{3}$ Post-TEVAR AEF may occur as a result of (1) the development of a false aneurysm owing to aortic wall trauma, (2) endoleak into the residual aneurysm sac, or (3) erosion of the stent graft through the aorta. ${ }^{2}$ Malalignment of a rigid endoprosthesis may also lead to penetration of the stent graft into the esophagus or pressure necrosis of the esophageal wall. 


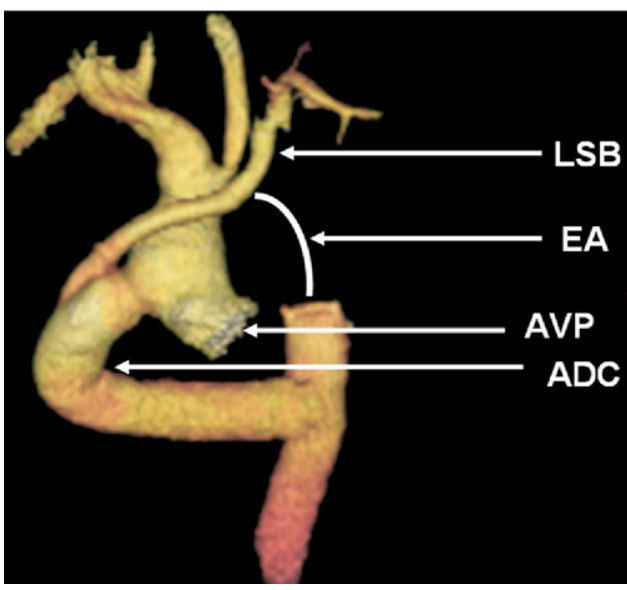

Figure 2. Reconstructed CT angiogram at 1 year. There is an ascending-descending aortic conduit (ADC) from the right side of the ascending aorta to the lower descending aorta. A side branch of the graft has been used to bypass (LSB) the excluded left subclavian artery. The aortic valve prosthesis (AVP) is shown. The aorta in the vicinity of the fistula is excluded (EA) from the aortic arch between the left common carotid and subclavian arteries and the mid-descending aorta.
We followed standard principles of fistula management, diverting the aorta away from the site of the presumed fistula and using visceral decompression to allow healing. ${ }^{4}$

AEF is a catastrophic complication of endovascular repair with limited therapeutic options. Definitive surgical treatment can lead to a successful outcome. ${ }^{5}$

\section{References}

1. Eggebrecht H, Baumgart D, Radecke K, von Birgelen C, Treichel U, Erbel R, et al. Aortoesophageal fistula secondary to stent-graft repair of the thoracic aorta. $J$ Endovasc Ther. 2004;11:161-7.

2. Hance KA, Hsu L, Eskew T, Hermreck AS. Secondary aortoesophageal fistula after endoluminal exclusion because of thoracic aortic transection. J Vasc Surg. 2003;37:886-8.

3. Knyshov GV, Sitar LL, Glagola MD, Atamanyuk MY. Aortic aneurysms at the site of the repair of coarctation of the aorta: a review of 48 patients. Ann Thorac Surg. 1996;61:935-9.

4. von Segesser LK, Tkebuchava T, Niederhauser U, Kunzil A, Lachat M Turina MI, et al. Aortobronchial and aortoesophageal fistulae as risk factors in surgery of descending thoracic aortic aneurysms. Eur J Cardiothorac Surg. 1997;12:195-201.

5. Czerny M, Zimpfer D, Fleck T, Mueller MR, Gottardi R, Cejna M, et al. Successful treatment of an aortoesophageal fistula after emergency endovascular thoracic aortic stent-graft placement. Ann Thorac Surg. 2005;80:1117-20

\title{
Occlusion of the left coronary ostium by an aortic valve leaflet
}

\author{
Shafi Mussa, MA, MRCS, ${ }^{a}$ Paul Miller, MBChB, DCH, FRCP, ${ }^{b}$ David J. Barron, MD, FRCP, FRCS, and
}

William J. Brawn, FRCS, FRACS, ${ }^{\text {a }}$ Birmingham, United Kingdom

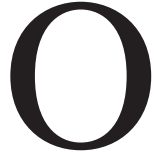

cclusion of the left coronary ostium by an aortic valve leaflet is a rare but well-described variant of aortic valve morphology. We report this finding in a neonate with a number of cardiac abnormalities, substantiating the theory that it is a congenital abnormality of aortic valve development.

From the Departments of Cardiothoracic Surgery and Pediatric Cardiol-

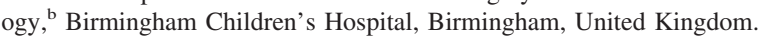

Received for publication July 25, 2007; accepted for publication Aug 7, 2007.

Address for reprints: William J. Brawn, FRCS, FRACS, Consultant Cardiothoracic Surgeon, Department of Cardiothoracic Surgery, Birmingham Children's Hospital, Steelhouse Lane, Birmingham B4 6NH, United Kingdom (E-mail: william.brawn@ bch.nhs.uk).

J Thorac Cardiovasc Surg 2007;134:1586-7

$0022-5223 / \$ 32.00$

Copyright $\odot 2007$ by The American Association for Thoracic Surgery doi:10.1016/j.jtcvs.2007.08.017

\section{Clinical Summary}

A 3-day-old boy who weighed $2.7 \mathrm{~kg}$ presented with poor feeding and lethargy after an uneventful normal vaginal delivery at term. Examination revealed tachypnea, poor peripheral pulses, and a systolic murmur. An echocardiogram revealed normal atrial arrangement, atrial septal defect with bidirectional flow, muscular outlet ventricular septal defect, subaortic stenosis (left ventricular outflow tract diameter of $4 \mathrm{~mm}$ ), dysplastic stenotic aortic valve with a maximum root diameter of $4.8 \mathrm{~mm}$ (Figure 1), type A interrupted aortic arch, moderate-sized ductus arteriosus, and normal-volume left ventricle with impaired systolic function. After stabilization with prostaglandin E2 $(7.5 \mathrm{ng} / \mathrm{kg} / \mathrm{min})$ and dobutamine $(5 \mu \mathrm{g} / \mathrm{kg} / \mathrm{min})$, surgery was undertaken at 9 days.

Operative findings included a bicuspid aortic valve with the large leftward leaflet fused to the aortic wall over the left coronary sinus. Sharp dissection at the sinotubular junction released the leaflet and de-roofed the sinus, revealing 2 distinct left coronary ostia. The remaining surgery comprised aortic arch repair with formation of a Damus-Kaye-Stansel anastomosis, formation of a double-outlet left ventricle by enlarging the ventricular septal defect, and implantation of a bovine pericardial patch committing the aorta and main pulmonary artery to the left ventricle. An 